\title{
Extended Study of the Flipped Instruction and Its Usefulness
}

\author{
https://doi.org/10.3991/ijoe.v15i03.9841 \\ Christopher Nwosisi \\ The College of Westchester, New York, USA \\ cnwosisiecw.edu
}

\begin{abstract}
The old-style pattern of instruction has been to allocate students to read textbooks and work on assigned problems outside of school, while listening to lectures and taking exams in class. With the introduction of Flipped instruction or a flipped classroom the students absorb new content online by watching video lectures, usually at home, and what used to be homework is now done in class with teachers offering more tailored direction and communication with students, instead of lecturing. Up to fifty percent of the course, content was flipped in this study. Results on six of the courses used will be presented and deliberated on.
\end{abstract}

Keywords-Flipped instruction and Flipped Classroom.

\section{$1 \quad$ Introduction}

Flipped instructions allow class time for practical work [1]. Students absorb by asking questions and doing. The innovated process benefit both the advanced and less advanced students because they can help each other [2].

In reversed instruction, the students typically use video lessons prepared by the teacher [3],[4] or third parties to first learn the topic by themselves. Students apply the knowledge by solving problems and doing practical work in class [5]-[6]. The Instructor guides the students when they have trouble, rather than communicating the initial lesson in person. Corresponding methods comprise [7] of project-based learning and differentiated instruction [8]. Educators are combining the advantages of flipped learning with the old in-class lecturing through tools like eduCanon that keep students answerable to video lessons at home-based through time-engrained developmental assessments [9].

The allocation of teacher time also changes with the reversing process. Customarily, the Instructor engrosses with the students who ask questions-but those who do not ask questions tend to need the utmost consideration. "We refer to those students as "silent failers," considered one instructor, claiming that reversing the processes allows her to assist those who require the utmost support rather than the most self-assured dent. Reversing changes instructors from "sage on the stage" to "guide on the side", permitting them to exercise educative guidance to independent students or assembly of scholars during the session [10]. 
The thought behind the flip is that Instructors can spend time working with students who need their help in the classroom - and students can work together to solve problems - rather than sitting home alone with work that they might not understand with nobody to ask for assistance.

Table 1. Students' perceptions survey results

\begin{tabular}{|c|c|c|c|}
\hline Questions & Agree & Disagree & Neutral \\
\hline I like this style to learning & $85 \%$ & $5 \%$ & $10 \%$ \\
\hline This style helped me learn the material better & $76 \%$ & $7 \%$ & $17 \%$ \\
\hline This style required more work & $50 \%$ & $17 \%$ & $33 \%$ \\
\hline I would want more of the material in the course taught this way & $67 \%$ & $17 \%$ & $16 \%$ \\
\hline I would want other courses to use this style to learn & $62 \%$ & $17 \%$ & $21 \%$ \\
\hline
\end{tabular}

The reason for this study is to confirm our previous study by adding four more courses. The paper is ordered as follows: Section 2 provides the Literature Review, Section 3 deliberates on the method and results, and section 4 presents the conclusion and proposals for future work.

\section{$2 \quad$ Literature Review}

The Literature review contains the previous results about Flipped or reversed instruction or hybrid courses. Mixed (Blended) learning courses are well-defined as "classes in, which instruction takes place in an old-style classroom setting augmented by computer-based or online activities which can replace classroom seat time" [11]. Jeffrey R. Young pointed [12], "a growing number of colleges are experimenting with hybrid $^{\text {ee }}$ or blended" models of teaching that replace some in-person meetings with virtual sessions." Scida and Saury [11] further argue that hybrid courses are becoming increasingly the norm in higher education in the United States as earlier predictions of the explosion of completely online courses have not been borne out in practice" (see [13]-[16]). Additionally, Young [12] argues that hybrid classes are less controversial among university faculty than offering old-style fully virtual courses and that "hybrid courses may be a better way than fully online courses to help busy commuter students."

Many supporters of hybrid courses say that their foremost incentive is to improve the educational engrossment for students and to relieve limited resource pressures on college campuses, pointing to research that reveals that using blended learning improves student success rates in learning outcomes and retention [17] and that hybrid courses ease campus classroom shortages and enrollment pressures [12]. Chuck Dziuban, director of the Research Initiative for Teaching Effectiveness at the University of Central Florida, says that his office's research shows that student success rates in hybrid courses on the Central Florida campus are "equivalent or slightly superior" to face-to-face courses, and that the hybrid courses have lower dropout rates than do fully online courses. Additionally, Chris Dede, professor of learning technologies at Harvard University's Graduate School of Education, stated, "A strong case is beginning to be made on the basis of research evidence that many students learn better 
online than face-to-face, and therefore a mixture is the best way. What percentage that mixture should be would vary from course to course [12]. Over the past decade, there have been many advances in the technology and pedagogy of hybrid, or blended learning, courses. Moore [18], Moore, and Kearsley [19] have looked at the role of blended learning within the distance education landscape and Staker [20] has examined the role of the disruptive innovation of online learning in the world of education. [21] looked specifically at emerging technologies that are continuing to enhance student-centered classrooms and [22] have looked at the recent practices and trends in blended learning from a global perspective. [23], [24] emphasized the role of community building and development of a community of inquiry in order to increase effectiveness and success of online teaching and learning. [25] found important relationships among teaching presence, cognitive presence, social presence, and students' perceived learning and satisfaction in the course. Finally, [26] argue that "The power of the hybrid course model is its flexibility and pedagogical effectiveness. Because it emphasizes active learning methods, it increases student interaction with other students and the instructor."

\section{$3 \quad$ Method and Results}

\subsection{Overview}

The early work was deemed "Phase I" of the institution's evaluation of flipped instruction and learning, with the purpose of expanding on the process should the results of the first phase prove encouraging. DFW Rates and average Non-DFW were used as metrics. The average non-DFW grades, the average above D will be used as a comparative assessment element for this research. The $\mathrm{F}$ grades and Withdrawals are clearly failures as Learning Outcomes. Both the Quantitative and Qualitative results from Phase I were very encouraging. Average grades increased, and even better, DFW rates are significantly reduced. Qualitative findings were also reassuring as $94 \%$ of students in this initial group responded that they liked this method to learning and $72 \%$ indicated that this approach "Helped [them] learn the material better". The effort was then extended with a Phase II, in which 4 course offerings were correspondingly reversed, including one Evening course, comprised of customarily adult students.

All the participating instructors were required to explain and record their method. Each instructor chose to flip roughly every other week's content, providing diversity of digital learning materials (videos, podcasts, docs, web-based tools) to be used outside of class, joined with in-class exercises, projects, collaborative group work, and work on assigned labs, in groups and individual.

Online Class Gears: As with Phase I, students are anticipated to have already completed several online homework prior to attending a class. The students are required to read the assigned book chapter. The students are also required to watch video lectures of instructions, typically totaling 40 - 60 minutes that cover a topic. Then students are encouraged to contribute to the online homework discussions and come to class with questions. Homework assignments are not graded until two days 
after the in-class session to clarify any misconception they may have about the material [27].

In Class Meeting: In each class meeting, the Instructor offers an outline of the course content. The students would have completed most of their outside requirements and would be ready with any questions that they needed to ask. After the questions are answered and the Instructor feels reassured that the students have proper understanding and clarity, the Instructor would then facilitate an in-class Lab activity to strengthen the student learning. The students would work on their Labs but are encouraged to collaborate with each other. At the same time, the Instructor provides help with the Lab as he moves from group to group and by answering any questions. After completing the Labs, the students are expected to be capable on that idea and are ready to take the quiz at that time [27].

Technologies Used: Packet tracer and Moodle are the main online technologies used in the Cisco Networking Basic pilot course. The Moodle enables the students to watch their online lectures as well as submit their completed Labs, which was done with Packet tracer. Packet tracer and Moodle are great resources to use outside of the classroom because of the many different methods they use to assist students to complete assignments. Each problem that the students encounter has links to various resources that they can use as an example. A given problem may have a link to a comparable problem that shows step by step what to do. These solutions help, along with other tools, that give students the resources that they need to understand the course content [27].

\subsection{Evaluation}

Qualitative and quantitative evaluation methods were designed and incorporated into the research. Quantitative methods include a comparison of final grades in the flipped course section to average grades and completion rates in prior offerings of the same courses, as well as possible comparisons of performance on assessments related to the flipped portions of each course to the assessments of the non-flipped portions. Table 2 shows the Quantitative results of current research as compared to 2012-2013. There were enhancements five out of the six courses. Five of six flipped classes experienced higher average rates in the $\mathrm{A}$ to $\mathrm{C}$ - range, and the average grade rose by about $2 \%$. This was not a statistically significant change.

Table 2. Average passing grade and improvement

\begin{tabular}{|l|c|c|c|}
\hline \multicolumn{1}{|c|}{ Course Number } & Current Study & $\mathbf{2 0 1 2 - 2 0 1 3}$ & Improvement \\
\hline NET-125 (DAY) & 88.3 & 82.5 & $5.8 \%$ \\
\hline NET-125 (EVENING) & 86.4 & 88.4 & $-2 \%$ \\
\hline OFT-115 (DAY) (2) & 90.5 & 88.7 & $1.8 \%$ \\
\hline GEN-330 (DAY) (2) & 88.3 & 87 & $1.3 \%$ \\
\hline
\end{tabular}

As a result of the Partial Flipped Class pilot, there is decline in the D and F grades and Withdrawals rates" DFW", see Table 3. Five of the six classes experienced reduced rates of $\mathrm{D}$ and $\mathrm{F}$ grades and Withdrawals. There was a $14.5 \%$ decrease in DFW 
rates across the six courses offered, on average, when compared to average rates for all same-shift availabilities of the courses during 2012 and 2013.

The decreases in DFW rates are reassuring and powerful outcomes. Grades of D, F, or Withdrawal play an important contributory role in the students' failure to recall and ultimately graduate. A method that can steadily reduce DFW Rate occurrence is certainly worth further exploration and pursuit.

Table 3. Average DFW rates

\begin{tabular}{|l|c|c|c|}
\hline \multicolumn{1}{|c|}{ Course Number } & Current Study & $\mathbf{2 0 1 2 - 2 0 1 3}$ & Improvement \\
\hline NET-125 (DAY) & $9.1 \%$ & $40.8 \%$ & Yes \\
\hline NET-125 (EVENING) & $20.0 \%$ & $23.8 \%$ & Yes \\
\hline OFT-115 (DAY) (2) & $19.6 \%$ & $20.9 \%$ & Yes \\
\hline GEN-330 (DAY) (2) & $23.3 \%$ & $15.9 \%$ & No \\
\hline
\end{tabular}

Table 4. Grades and DFW rate comparisons

\section{Grades \& DFW Rate Comparisons}

6 Piloted Partially Flipped Courses vs. Non-Flipped Prior Offerings of Same Course

\begin{tabular}{|c|c|c|c|}
\hline & $\begin{array}{c}\text { Average non- } \\
\text { DFW Passing } \\
\text { Grades }\end{array}$ & $\begin{array}{c}\text { Average } \\
\text { DFW Rates }\end{array}$ & \\
\hline NET125 - All 2012 - 2013 Day Offerings & 82.5 & $40.8 \%$ & \\
\hline NET125 - 2014 Day Flipped Class & 88.3 & $9.1 \%$ & \\
\hline NET125 - All 2012 - 2013 Evening Offerings & 88.4 & $23.8 \%$ & \\
\hline NET125 - 2014 Adult Flipped Class & 86.4 & $20.0 \%$ & \\
\hline OFT115 - All 2012-2013 (Day) Offerings & 88.7 & $20.9 \%$ & \\
\hline OFT115 - (Two) 2014 Flipped Day Classes & 90.5 & $19.6 \%$ & \\
\hline GEN330 - All 2012-2013 (Day) Offerings & 87.0 & $15.9 \%$ & \\
\hline GEN330 - (Two) 2014 Flipped Day Classes & 88.3 & $23.3 \%$ & \\
\hline ALL PRIOR COURSES COMBINED & 86.9 & $24.1 \%$ & \\
\hline ALL FLIPPED COURSES COMBINED & 88.9 & $20.6 \%$ & \\
\hline$\%$ Improvement & $2.3 \%$ & $14.5 \%$ & \% Decrease \\
\hline \multicolumn{4}{|c|}{5 out of 6 Courses Experienced an Increase in Average Non-DFW Grades* } \\
\hline \multicolumn{4}{|c|}{5 out of 6 Courses Experienced an Decrease in Average DFW Rates* } \\
\hline
\end{tabular}

Qualitative evaluations are based on an investigation of student comments, and instructor observations of the course and the flipped class delivery method. This paper addresses students' observations only. 


\subsection{Qualitative evaluation: Student observations survey}

To measure student's thoughts on how the flipped delivery method affected their learning, five Questions were asked on this survey. Strongly Disagree, Disagree, Neither Agree nor Disagree, Agree, and Strongly Agree, were response options for each question. Responses were summarized into 3 groups (by combining "Strongly Agree" and "Agree" together and combining "Strongly Disagree" and "Disagree" together). Table 1, shows the Qualitative outcomes of this study.

Most of the students (85\%) in question No. 1 selected "Strong Agree" or "Agree" for this question (see Table I). $76 \%$ of students in question No. 2, a significant majority, agreed that the flipped instruction method helped them learn the material better. In question No. 3, over half of the students felt that flipped instruction and learning did require more work, which is not surprising. In question $4,67 \%$ of students answered in the affirmative on this question. In question 5, 62\% of students agreed that they would want other courses to use this style to learn. It is interesting since most of the students said that they like the style and that they learned more. We believe that this might be due to multiple factors such as: the early class time, which is 8:00 am, students do not like to start their homework before class and they do not want to appear unknowledgeable on a certain topic [27]. These outcomes are quite supportive of the use of flipped instruction methods in students' educative participations.

\section{Discussion and Conclusion}

Mutually, Qualitative and Quantitative outcomes from the Partial Flipped Classed Pilot have been aspiring. DFW rates reduced by over $14 \%$ on average, see Table 4. $85 \%$ of students answered that they liked this method to learning and $76 \%$ indicated that this method "Helped [them] learn the material better", from a qualitative perspective. This study exemplifies that using the Flipped classroom concept for up to fifty percent of the course content is a great help to the students. Some students do not grasp the concept in the beginning. The Flipped instruction concept facilitates communication between students and their Instructors, and among students. Flipped classroom leads to improved learning outcomes. This insight supports students to efficiently learn to accomplish skill, knowledge, and to demonstrate a suitable approach towards learning. The outcomes of the study suggest need for further research. Currently, additional study to investigate the influence of flipped learning to DFW rates is ongoing. Further research is needed. First, the process should be accomplished the same study with additional courses with students and instructors' involvement. Second, observe the Flipped classroom efficacy with students of special needs. Flipped or reversed instruction format may be used in preparatory and remedial instruction. The Instructor should maintain simplicity and start little. 


\section{$5 \quad$ Acknowledgement}

The College of Westchester, White Plains, New York provided the opportunity for this study. I express my sincere gratitude to the Institution and to some of my Colleagues.

\section{References}

[1] "The Flipped Classroom: Turning Traditional Education on Its Head". Knewton.

[2] Rosenberg, Tina (2013-10-09). "Turning Education Upside Down". New York Times. Retrieved 2013-10-11

[3] Marco Ronchetti (June 2010), "Using video lectures to make teaching more interactive", International Journal of Emerging Technologies in Learning (iJET)

[4] Greg Topp (6 Oct 2011), "Flipped classrooms take advantage of technology", USA Today

[5] "Flipping the classroom", The Economist, 17 Sep 2011

[6] Diana Mehta (8 Sep 2011), "Video in the class keeps savvy students engaged", The Canadian Press (Toronto)

[7] Daniel Pink (12 Sep 2010), "Flip-thinking - the new buzz word sweeping the US", The Daily Telegraph (London)

[8] Alvarez, Brenda. "Flipping the Classroom: Homework in Class, Lessons at Home". National Education Association. Retrieved 22 February 2012.

[9] Bill Tucker (Winter 2012), "The Flipped Classroom", EducationNext

[10] Jonathan Olsen and Sarah Gross (March 21, 2014). "Skills Practice - Alternative History as Narrative". New York Times.

[11] E. E. Scida and R. E. Saury, "Hybrid courses and their impact on Student and classroom performance:

[12] A case study at the University of Virginia," CALICO Journal, vol. 23, no. 3, pp. 517-531, 2006.

[13] J. R. Young, "Hybrid"e Teaching Seeks to End the Divide between Traditional and Online Instruction," Chronicle of Higher Education, vol. 48, no. 28, pp. A33-A34, 2002.

[14] M. T. Ijab, R. Anwar, and S. Hamid, "Teaching and learning of e-commerce courses via hybrid e learn-ing model in Unitar," Journal of Electronic Commerce in Organizations, vol. 2, no. 2, pp. 79-94, 2004. https://doi.org/10.4018/jeco.2004040107

[15] E. B. Lindsay, "The best of both worlds: Teaching a hybrid course," Academic Exchange Quarterly, vol. 8, no. 4, pp. 16-20, 2004.

[16] D. Sauers and R. C. Walker, "A comparison of traditional and technology-assisted instructional methods in the business

[17] H. G. Willet, "Not one or the other but both: Hybrid course delivery using WebCT," The Electronic Library, vol. 20, no. 5, pp. 413-419, 2002. https://doi.org/10. $1108 / 02640470210447847$

[18] T. Boyle, C. Bradley, P. Chalk, Jones, and P. Pickard, "Using blended learning to improve student success rates in learning to program," Journal of Educational Media, vol. 28, no. 2-3, pp. 165-178, 2003. https://doi.org/10.1080/1358165032000153160

[19] M. G. Moore, Handbook of distance education, Routledge, 2013. [19] M. G. Moore and G. Kearsley, https://doi.org/10.4324/9780203803738

[20] Distance education: A systems view of Online learning, CengageBrain.com, 2011. 
[21] H. Staker, "The Rise of K-12 Blended Learning: Profiles of Emerging Models," Innosight Institute, 2011.

[22] C. R. Tucker, Blended Learning in Grades 4-12: Leveraging the Power of Technology to Create Student-Centered Classrooms, SAGE, 2012.

[23] C. J. Bonk and C. R. Graham, The handbook of blended learning: Global perspectives, local designs, Wiley. Com, 2012.

[24] Z. Akyol and D. R. Garrison, "Community of inquiry in adult online Learning: Collaborative-constructivist approaches," in T. T. Kidd (Ed.), Adult learning in the digital age: Perspectives on online Technologies and outcomes (Ch.VI), Hershey, PA: IGI Global, 2009.

[25] Z. Akyol, N. Vaughan, and D. R. Garrison, "The impact of course duration on the development of a community of inquiry," Interactive Learning Environments, 2011. https://doi.org/10.1080/10494820902809147

[26] Z. Akyol and D. R. Garrison, "The development of a community of inquiry over time in an online course: Understanding the progression and integration of social, cognitive and teaching presence,"

[27] Journal of Asynchronous Learning Networks, vol. 12, no. 2-3, pp. 3-23, 2008.

[28] Aycokc, C. Garnham, and R. Kaleta. (2002). Lessons learned from the Hybrid Course Project. Teaching with Technology Today, Online.

[29] C. Nwosisi, "A Study of the Flipped Classroom and Its effectiveness in Flipping Thirty Percent of the Course Content," International Journal of Information and Education Technology, Vol. 6, No. 5, May 2016 https://doi.org/10.7763/IJIET.2016.V6.712

\section{$7 \quad$ Authors}

Dr. Christopher Nwosisi attained his Doctorate Degree in Computing from Pace University, Master of Science in Management of Technology from Polytechnic University and BA in Computer Science from Hunter College of the City University of New York. He has co-authored several papers in International Conferences and Scientific Journals. He has served as co-program chair, Session chair and as keynote speaker at various International Conferences. At present, he is a Professor and an Associate Chair at The College of Westchester in White Plains, New York. He had received Faculty Recognition Awards, the Shining Star award in Teaching and numerous Presidential Commendations from the College of Westchester. He received the Upsilon Pi Epsilon Honors award for the Computing and Information Disciplines from Pace University in 2010. He received the IEEE senior membership award in 2007. He received the Recognition and Appreciation Awards from the Association for System Management in 1993 and 1994 respectively. Dr. Nwosisi has over 25 years of professional experience and over 23 years of teaching experience. His current research interests include Teaching Methodology, Decision Tree, Machine Learning, Data mining, and Pattern recognition.

Article submitted 10 November 2018. Resubmitted 21 November 2018. Final acceptance 15 January 2019. Final version published as submitted by the author. 